\title{
Effects of Chronic Treatment with Calcium Channel Blockers or Angiotensin Converting Enzyme Inhibitors on Renal Function in Streptozotocin-Treated Hypertensive Diabetic Rats
}

\author{
Kazunori Yoshida, Minoru Yasujima*, Masahiro Kohzuki, Masayuki Kanazawa, and Keishi Abe
}

\begin{abstract}
To assess renal benefits of calcium channel blockers (CCBs) and angiotensin converting enzyme inhibitors (ACEIs) in diabetic rats with renal impairment, we administered CCBs, nifedipine (NIF) and benidipine (BEN), or ACEIs, captopril (CAP) and trandolapril (TRA), for 12 weeks, and studied changes in systolic blood pressure (SBP) and urinary protein excretion (UP) in uninephrectomized spontaneously hypertensive rats and Wistar-Kyoto rats with diabetes mellitus induces by streptozotocin administration (WKY-STZ and SHR-STZ). In WKY-STZ, both the CCBs and the ACEIs decreased SBP and UP similarly. UP of SHR-STZ was more than that of WKY-STZ. Both the CCBs and the ACEIs attenuated the development of hypertension in SHR-STZ similarly. However, UP in the ACEIs group was significantly less than that of the control (no treatment), whereas UP in the CCBs group was not significantly less than that of the control. These results indicate that hypertension may accelerate diabetic nephropathy. They also indicate that reduction of systemic blood pressure does not always lessen the renal injury in this model of rats. ACEIs were more potent in reducing proteinuria than CCBs in this diabetic model in rats partly because ACEIs may preferentially reduce the intraglomerular capillary pressure. (Hypertens Res 1994; 17: 35-41)
\end{abstract}

Key Words: diabetic nephropathy, nifedipine, benidipine, captopril, trandolapril, Wistar-Kyoto rats, spontaneously hypertensive rats

Systemic hypertension is a well-known cause of progressive renal injury in both humans and experimental animals $(1,2)$. Clinical and animal studies have suggested that antihypertensive therapy reduces the rate of decline in renal function in established diabetic renal disease and non-diabetic progressive renal diseases (3-7). Recent evidence suggests that the ability of antihypertensive therapy to protect the kidney relates in large part to the glomerular hemodynamic consequences of therapy (8). Prevention of glomerular capillary hypertension in diabetic rats by an angiotensin converting enzyme inhibitor (ACEI), enalapril, effectively retarded the subsequent development of glomerular structural injury and proteinuria (9). Experimental and preliminary clinical studies suggested that not all antihypertensive regimens afford equal renal protection, and that agents which lower the glomerular hypertension may provide maximal protection to the kidney exposed to the risk of progressive glomerular injury $(8,10)$. Although calcium channel blockers (CCBs) are potent and well-tolerated antihypertensive agents, the potential role of CCBs in attenuat- ing the progression of diabetic renal disease or chronic renal disease has not been welldocumented. It is known that a model combining genetic hypertension with streptozotocin-induced diabetes has accelerated nephropathy, as determined by both functional and structural parameters, compared to that of a normotensive diabetic model (11, 12). Therefore, in the the present study, we chronically administered two different classes of antihypertensive agents, CCBs and ACEIs, to this diabetic model in rats in order to evaluate the effects of these drugs on blood pressure and the progression of proteinuria. Since unilateral nephrectomy in the rat enhances the severity of diabetic glomerular lesions $(13,14)$, we removed the unilateral kidney from the rats in the present study.

\section{Methods}

Eight-week-old male normotensive Wistar-Kyoto rats (WKY) and spontaneously hypertensive rats (SHR) were used (Charles River Japan, Atsugi, Japan). Under light ether anesthesia, the right kid-

From the Second Department of Internal Medicine and ${ }^{*}$ Institute of Rehabilitation Medicine, Tohoku University School of Medicine, Sendai, Japan.

Address for Reprints: Masahiro Kohzuki, M.D., Ph.D., Second Department of Internal Medicine, Tohoku University School of Medicine, 1-1, Seiryo-cho, Aoba-ku, Sendai 980, Japan.

Recieved April 9, 1993; accepted in revised form September 21, 1993. 
ney was removed through a flank incision. One week later, the rats were intraperitoneally injected with streptozotocin (STZ, Sigma Chemical Co., St. Louis, Missouri, USA). Since SHR are known to be more susceptible to the diabetogenic effects of STZ than WKY (15), the doses of STZ were adjusted to $35 \mathrm{mg} / \mathrm{kg}$ in SHR and $45 \mathrm{mg} / \mathrm{kg}$ in WKY, respectively. The STZ was dissolved in $10 \mathrm{mM}$ citrate buffer $(\mathrm{pH} \mathrm{4.5)}$ just before use. Urine was tested for glucose to document glycosuria 3-4 days after the STZ administration. Only those rats with urine glucose concentrations of more than $500 \mathrm{mg} / \mathrm{dl}$ were subsequently employed in the study. The rats were fed a regular diet (Funabashi F2, Funabashi Farm, Chiba, Japan, $0.19 \%$ sodium, $0.25 \%$ potassium, $20.8 \%$ protein by weight) and had free access to tap water. One week after the STZ administration (10 weeks old), baseline measurements of blood pressure and urinary protein excretion were performed. Then the WKY and SHR were randomly allocated to receive nifedipine (NIF, $n=7$, Bayer Pharmaceut., Co., Tokyo, Japan), benidipine (BEN, $n$ $=7$, Kyowa Hakko Kogyo Co., Tokyo, Japan), captopril (CAP, $n=7$, Sankyo Co., Tokyo, Japan), trandolapril (TRA, $n=7$, Nippon Roussel Co., Tokyo, Japan), and vehicle treatment $(n=7)$ as controls. NIF $(20 \mathrm{mg} / \mathrm{kg} /$ day $)$ and BEN $(6 \mathrm{mg} / \mathrm{kg} /$ day) were dissolved in polyethylene glycol 400 (Wako Pure Chemicals Industries LTD., Osaka, Japan) and administered by daily oral gavage. To attain a comparable depressor effect, nifedipine was administered twice a day $(10 \mathrm{mg} / \mathrm{kg}$, every $12 \mathrm{~h})$ to compensate for its short half-life (16), whereas benidipine was administered once a day. CAP $(50 \mathrm{mg} /$ $\mathrm{kg} /$ day) and TRA ( $1 \mathrm{mg} / \mathrm{kg} /$ day) were dissolved in the drinking water. All rats were maintained in a humidity-and temperature-controlled room during the study. Each rat was placed in a metabolic cage designed to prevent feces-urine contact (Model ST, Sugiyamagen, Tokyo, Japan) at the age of 9 weeks, 10 weeks and thereafter every 4 weeks for up to 22 weeks for collection of $24 \mathrm{~h}$ urine samples, and measurement of fluid and chow intake. Concentrations of CAP and TRA in the drinking water were adjusted every week by measuring fluid intake and body weight. Systolic blood pressure was also monitored by the indirect new tail cuff method (UEDA UR 1000, Ueda Industries Co., Tokyo, Japan) without anesthesia. The systolic blood pressure measured by this method correlated well with the direct systolic blood pressure (17). At the age of 22weeks, rats were sacrificed and trunk blood was obtained for determination of levels of blood glucose, blood urea nitrogen, serum creatinine, serum total protein, and serum total cholesterol. The left kidney was weighed. Urinary protein was measured by colorimetric method (Tonein-TP, Otsuka Pharmaceut., Co., Tokyo, Japan). Blood glucose, blood urea nitrogen, serum creatinine, serum total protein and serum total cholesterol were measured by a standard auto-analyzer technique.

All results were expressed as means \pm SEM. The data were statistically analyzed using unpaired Student's $t$-test. For the data on body weight, systolic

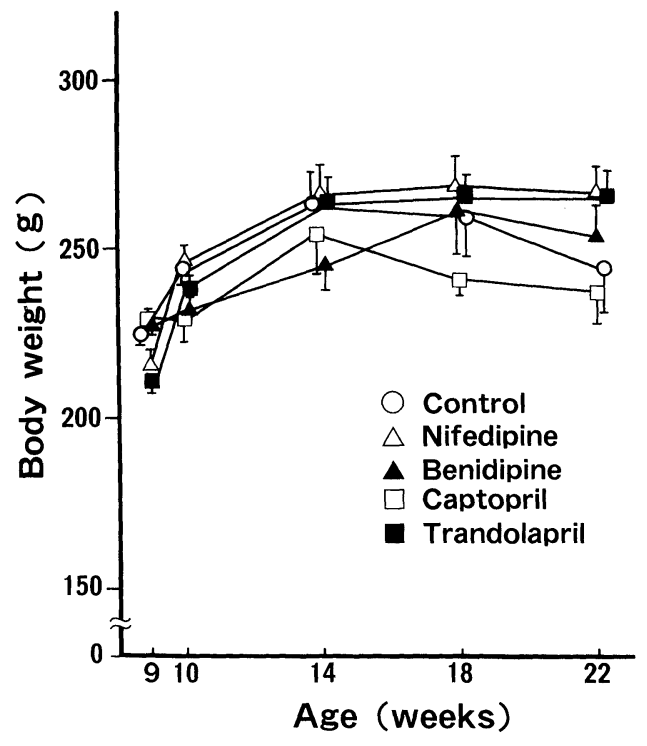

Fig. 1. Time course of body weight in diabetic WistarKyoto rats $(W K Y)$, receiving vehicle alone (control), nifedipine $(20 \mathrm{mg} / \mathrm{kg} /$ day), benidipine (6 $\mathrm{mg} / \mathrm{kg} /$ day $)$, captopril $(50 \mathrm{mg} / \mathrm{kg} /$ day $)$ or trandolapril $(1 \mathrm{mg} / \mathrm{kg} /$ day $)$. Data are means $\pm S E M$. Analysis of variance for repeated measurements (ANOVA) revealed no significant difference between the groups treated with nifedipine, benidipine, captopril, trandolapril and the control group.

blood pressure and urinary protein excretion, comparisons among different groups of rats over the study period were performed by analysis of variance with repeated measures. Statistical significance was defined as $p<0.05$.

\section{Result}

The Effects of CCBs and ACEIs on Blood Pressure and Renal Function in Diabetic WKY

There were no significant differences in body weight, systolic blood pressure and urinary protein excretion among the 5 groups before the induction of diabetes and one week thereafter. Body weight in each treated group was not significantly different from that in the control during the experimental period (Fig. 1). Systolic blood pressure in the control group, being $142.8 \pm 1.4 \mathrm{mmHg}$ at 10 weeks of age, elevated significantly to $165.0 \pm 2.0 \mathrm{mmHg}$ at 22 weeks of age ( $p<0.01$, Fig. 2). In contrast, the increase in blood pressure was attenuated in a similar manner in all treated groups during the experimental period $(p<0.05$ by ANOVA, respectively). Urinary protein excretion in the control group, being $23.9 \pm 2.0 \mathrm{mg} /$ day at 10 weeks of age, increased significantly to $52.6 \pm 6.8 \mathrm{mg} /$ day at 22 weeks of age $(p<0.01)$, (Fig. 3). Urinary protein excretion in each treated group was significantly less than that in the control group at 18 and 22 weeks of age (ANOVA, $p<0.05$, respectively). Differences among the 4-treated groups in urinary protein excretion were not significantly different during the 


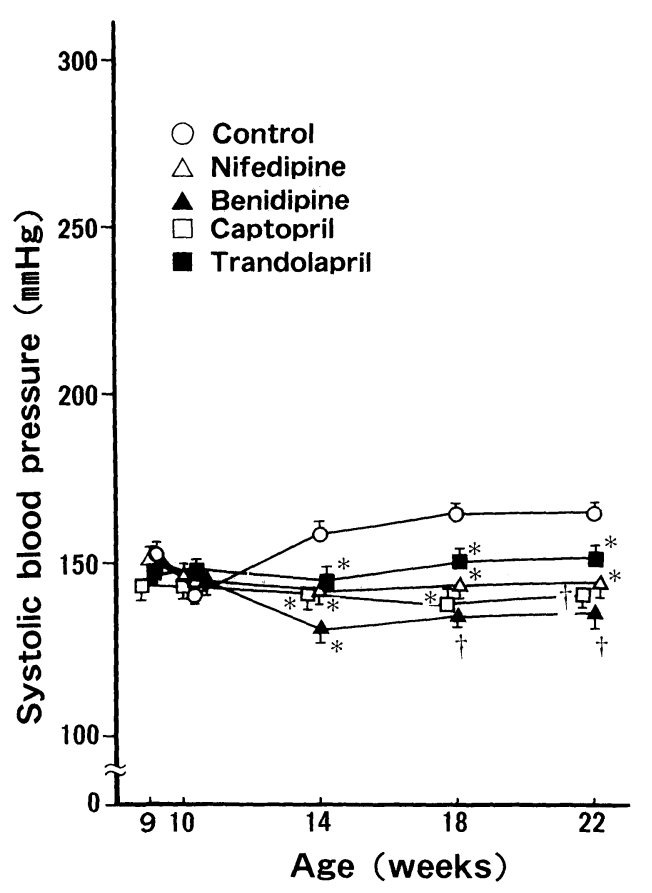

Fig. 2. Time course of systolic blood pressure in diabetic Wistar-Kyoto rats (WKY), receiving vehicle alone (control), nifedipine $(20 \mathrm{mg} / \mathrm{kg} /$ day $)$, benidipine ( $6 \mathrm{mg} / \mathrm{kg} /$ day), captopril $(50 \mathrm{mg} / \mathrm{kg} /$ day) or trandolapril (1 $\mathrm{mg} / \mathrm{kg} /$ day $)$. Data are means $\pm S E M$. Systolic blood pressure in diabetic $W K Y$ receiving nifedipine, benidipine, captopril or trandolapril was significantly different from that in the control group by ANOVA $\left(\mathrm{p}<0.05\right.$, respectively). ${ }^{*} \mathrm{p}<0.05,{ }^{\dagger} \mathrm{p}<$ 0.01 compared with the control group of the same week by Student's t-test.

experimental period. Table 1 summarizes parameters following treatment for 12 weeks. Blood urea nitrogen in both the CAP-treated group and the TRA-treated group was significantly lower than that in the control $(p<0.05, p<0.01$, respectively). There were no significant differences in serum creatinine, serum total protein and cholesterol among the 5 groups. Blood glucose in the BENtreated group was significantly lower than that of

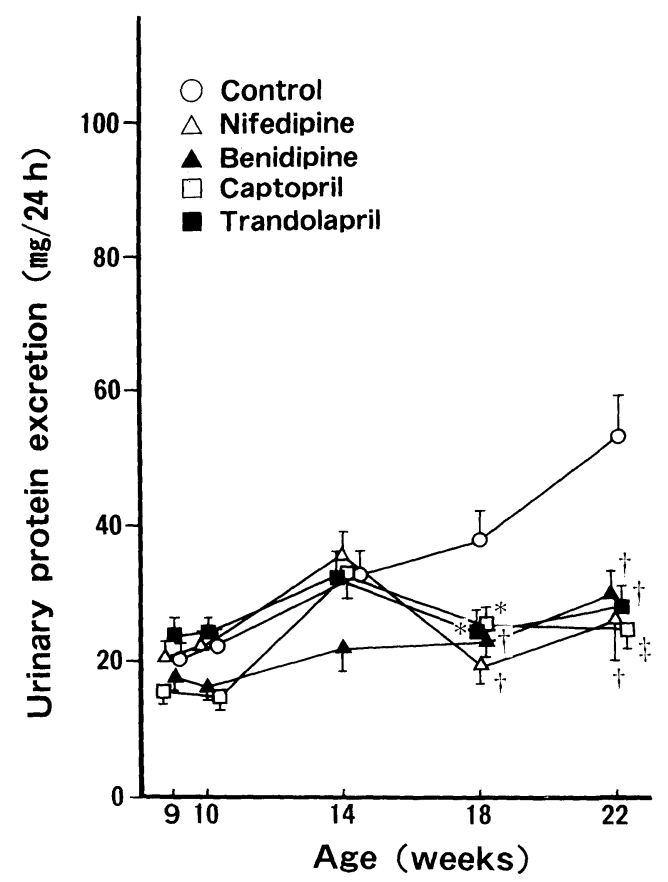

Fig. 3. Time course of urinary protein excretion in diabetic Wistar-Kyoto rats (WKY), receiving vehicle alone (control), nifedipine $(20 \mathrm{mg} / \mathrm{kg} /$ day $)$, benidipine $(6 \mathrm{mg} / \mathrm{kg} /$ day), captopril (50 $\mathrm{mg} / \mathrm{kg} /$ day) or trandolapril $(1 \mathrm{mg} / \mathrm{kg} /$ day). Data are means $\pm S E M$. Urinary protein excretion in diabetic WKY receiving nifedipine, benidipine, captopril or trandolapril was significantly different from that in the control group by ANOVA ( $\mathrm{p}<0.05$, respectively). ${ }^{*} \mathrm{p}<0.05$, ${ }^{\dagger} \mathrm{p}<0.01,{ }^{\ddagger} \mathrm{p}<0.001$ compared with the control group of the same week by Student's t-test.

the control $(p<0.01)$. Kidney weight per $100 \mathrm{~g}$ of body weight was significantly lighter in the NIFtreated, BEN-treated or TRA-treated groups than in the control $(p<0.01, p<0.05$, respectively).

The Effects of CCBs and ACEIs on Blood Pressure and Renal Function in Diabetic SHR

There were no significant differences in body weight, systolic blood pressure and urinary protein

Table 1. Parameters Following Treatment with Nifedipine, Benidipine, Captopril, Trandolapril or Vehicle (Control) for 12 Weeks in Diabetic Wistar-Kyoto Rats (WKY)

\begin{tabular}{lccccc}
\hline & $\begin{array}{c}\text { Control } \\
n=7\end{array}$ & $\begin{array}{c}\text { Nifedipine } \\
n=7\end{array}$ & $\begin{array}{c}\text { Benidipine } \\
n=7\end{array}$ & \multicolumn{2}{c}{ Captopril } \\
$n=7$ & $\begin{array}{c}\text { Trandolapril } \\
n=7\end{array}$ \\
\hline BUN (mg/dl) & $33.2 \pm 1.6$ & $28.8 \pm 1.5$ & $29.3 \pm 3.3$ & $24.9 \pm 2.8^{*}$ & $24.4 \pm 2.0^{* *}$ \\
Scr $(\mathrm{mg} / \mathrm{dl})$ & $0.64 \pm 0.05$ & $0.64 \pm 0.03$ & $0.66 \pm 0.07$ & $0.73 \pm 0.12$ & $0.63 \pm 0.02$ \\
BG $(\mathrm{mg} / \mathrm{dl})$ & $565 \pm 10$ & $554 \pm 5$ & $485 \pm 20^{* *}$ & $510 \pm 31$ & $543 \pm 10$ \\
TP $(\mathrm{g} / \mathrm{dl})$ & $5.3 \pm 0.1$ & $5.1 \pm 0.1$ & $5.3 \pm 0.1$ & $5.2 \pm 0.2$ & $5.3 \pm 0.1$ \\
Tcho $(\mathrm{mg} / \mathrm{dl})$ & $119 \pm 4$ & $115 \pm 3$ & $111 \pm 5$ & $125 \pm 3$ & $109 \pm 4$ \\
BW $(\mathrm{g})$ & $243 \pm 13$ & $266 \pm 7$ & $254 \pm 9$ & $236 \pm 9$ & $265 \pm 8$ \\
KW/100 g BW & $0.87 \pm 0.04$ & $0.70 \pm 0.01^{*}$ & $0.68 \pm 0.05^{*}$ & $0.84 \pm 0.07$ & $0.74 \pm 0.02^{*}$ \\
\hline
\end{tabular}

Results are expressed as mean \pm SEM. BUN, blood urea nitrogen; Scr, serum creatinine; BG, blood glucose; TP, serum total protein; Tcho, serum total cholesterol; $\mathrm{BW}$, body weight; $\mathrm{KW}$, kidney weight. ${ }^{*} p<0.05$, ${ }^{* *} p<0.01 v s$. control. 


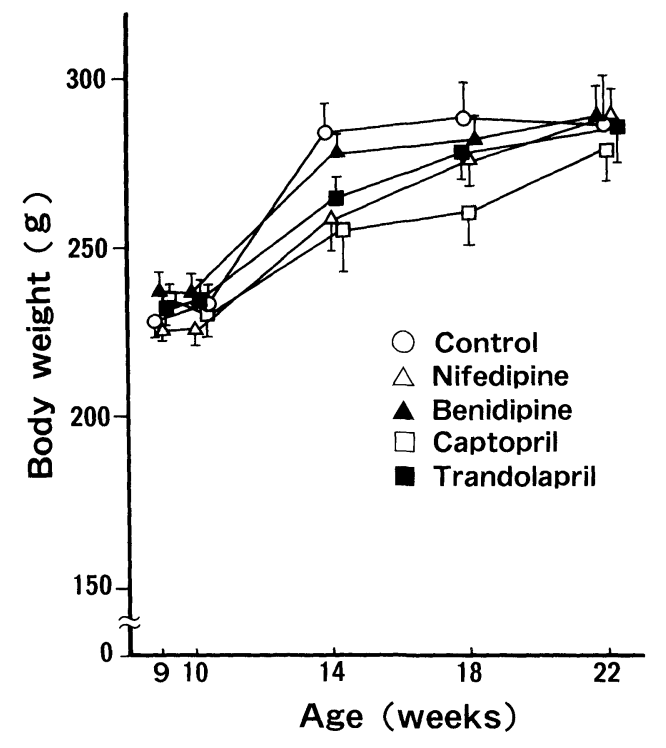

Fig. 4. Time course of body weight in diabetic spontaneously hypertensive rats $(S H R)$, receiving vehicle alone (control), nifedipine $(20 \mathrm{mg} / \mathrm{kg} /$ day $)$, benidipine $(6 \mathrm{mg} / \mathrm{kg} /$ day), captopril $(50 \mathrm{mg} / \mathrm{kg} /$ day) or trandolapril $(1 \mathrm{mg} / \mathrm{kg} /$ day). Data are means $\pm S E M$. Analysis of variance for repeated measurements (ANOVA) revealed no significant difference between the groups treated with nifedipine, benidipine, captopril, trandolapril and the control group.

excretion among the 5 groups before the induction of diabetes and one week thereafter. Body weight in each treated group was not significantly different from that in the control group during the experimental period (Fig. 4). Systolic blood pressure in the control group, being $201.0 \pm 3.2 \mathrm{mmHg}$ at 10 weeks of age, which was significantly higher than that in the control group of WKY $(p<0.001)$, rose significantly to $235.5 \pm 3.4 \mathrm{mmHg}$ at 22 weeks of age $(p<0.01$, Fig. 5). Systolic blood pressure in all treated groups was significantly lower than that in the control group at 14, 18 and 22 weeks of age ( $p$ $<0.01$, respectively), although systolic blood pressure levels in these groups were significantly higher than that in the control group of WKY $(p<0.01$ by ANOVA, respectively). Urinary protein excretion in the control group, being $26.8 \pm 0.8 \mathrm{mg} /$ day at 10 weeks of age increased remarkably to $108.9 \pm 8.6$ $\mathrm{mg}$ /day at 22 weeks of age $(p<0.001$, Fig. 6), which was approximately twice that in the control WKY $(p<0.05)$. Compared to the control, both CAP- and TRA-treated groups showed significantly lower urinary protein excretion ( $p<0.05$ by ANOVA, respectively). On the contrary, both NIF- and BENtreated groups failed to show reduced urinary protein excretion.

Table 2 presents parameters following treatment for 12 weeks. Blood urea nitrogen, serum creatinine, total cholesterol and body weight in the treated groups were not significantly different from the values in the control. Blood glucose in the NIFtreated group was significantly lower than that in

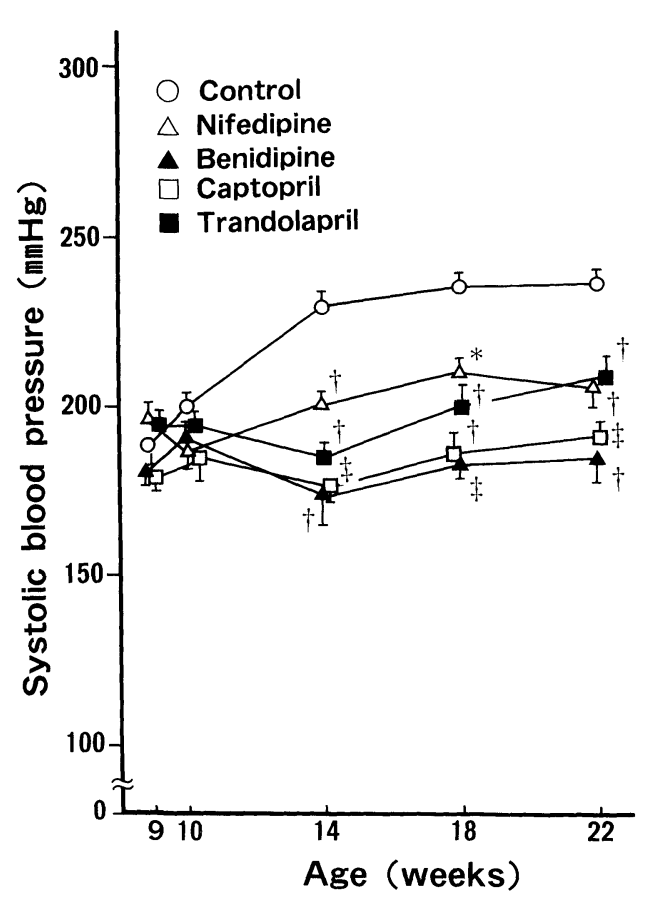

Fig. 5. Time course of systolic blood pressure in diabetic spontaneously hypertensive rats (SHR), receiving vehicle alone (control), nifedipine $(20 \mathrm{mg} / \mathrm{kg} /$ day $)$, benidipine $(6$ $\mathrm{mg} / \mathrm{kg} /$ day), captopril $(50 \mathrm{mg} / \mathrm{kg} /$ day) or trandolapril (1 $\mathrm{mg} / \mathrm{kg} /$ day). Data are means \pm SEM. Systolic blood pressure in diabetic SHR receiving nifedipine, benidipine, captopril or trandolapril was significantly different from that in the control group by ANOVA ( $\mathrm{p}<0.01$, respectively). ${ }^{*} \mathrm{p}$ $<0.05,{ }^{\dagger} \mathrm{p}<0.01,{ }^{+} \mathrm{p}<0.001$ compared with the control group of the same week by Student's t-test.

the control group $(p<0.05)$. Serum total protein in the NIF-treated group was higher than that in the control $(p<0.05)$. Kidney weight per $100 \mathrm{~g}$ of body weight in the NIF-treated group was significantly lighter than that in the control $(p<0.05)$.

\section{Discussion}

Taguma et al. (18) first reported that captopril reduced severe proteinuria in patients with advanced diabetic nephropathy. Since then, several studies have been carried out to evaluate the proteinuria reducing or renal protective effects of ACEIs in patients with chronic renal failure or diabetic nephropathy $(5,7,19,20)$ and in animal models of chronic renal disease $(9,10,21,22)$. Hypotensive therapy plays an important role in preventing the progression of nephropathy in humans and animal models. However, experimental and preliminary clinical data suggest that not all antihypertensive regimens afford equal renal protection, and that agents which control intraglomerular hypertension may provide maximal protection for the kidney at risk for progressive glomerular injury $(8,10,23)$. Therefore, we examined the effects of ACEIs and CCBs on the progression of diabetic nephropathy in rats treated 


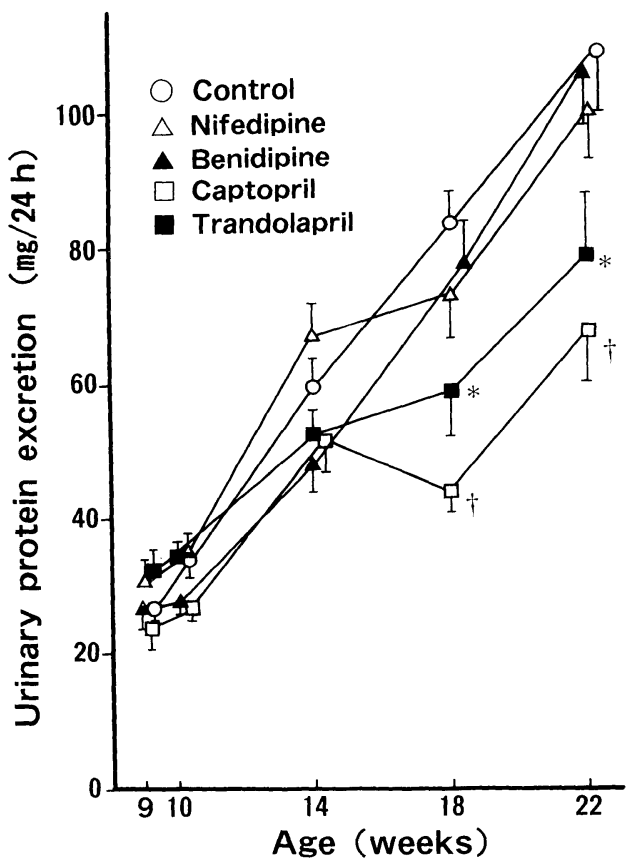

Fig. 6. Time course of urinary protein excretion in diabetic spontaneously hypertensive rats $(S H R)$, receiving vehicle alone (control), nifedipine $(20 \mathrm{mg} / \mathrm{kg} /$ day $)$, benidipine $(6 \mathrm{mg} / \mathrm{kg} /$ day $)$, captopril $(50 \mathrm{mg} / \mathrm{kg} /$ day) or trandolapril $(1 \mathrm{mg} / \mathrm{kg} /$ day $)$. Data are means $\pm S E M$. Urinary protein excretion in diabetic $S H R$ receiving captopril or trandolapril was significantly different from that in the control group by $A N O V A\left(\mathrm{p}<0.05\right.$, respectively). ${ }^{*} \mathrm{p}<0.05,{ }^{\dagger} \mathrm{p}<0.01$, compared with the control group of the same week by Student's t test.

with streptozotocin.

Proteinuria progressively increased in both diabetic WKY and diabetic SHR over the experimental period, which is consistent with the development of diabetic nephropathy. In addition, proteinuria in diabetic SHR was more severe than that in diabetic WKY in agreement with previous reports $(11,12)$. These results indicate that hypertension may accelerate diabetic nephropathy.
Moreover, in the present study, we clearly demonstrated that ACEIs, captopril and trandolapril, reduced proteinuria in both diabetic WKY and diabetic SHR. On the other hand, treatment with CCBs, NIF and BEN, reduced urinary protein excretion in diabetic WKY but not in diabetic SHR in spite of comparable blood pressure reduction. These results indicate a reduction in systemic blood pressure does not always lessen the renal injury in this model in rats. ACEIs could be more potent in reducing proteinuria than $\mathrm{CCBs}$ in this diabetic model. The differences in the outcome between these two classes of treatment, CCBs and ACEIs, were not due to different degrees of systemic blood pressure control. One explanation may lie in differences in their intrarenal actions and in differences in the afferent arteriolar resistance of SHR and WKY.

Glomerular hypertension may exist in the presence of normal systemic arterial pressure. A prominent example of glomerular hypertension without systemic hypertension is that associated with diabetes mellitus $(9,24,25)$. Systemic hypertension does not necessarily induce glomerular capillary hypertension. A prominent example of systemic hypertension without glomerular hypertension is SHR. The glomerulus is protected from high systemic pressure by virtue of relative afferent arteriolar vasoconstriction in SHR (26). In the present study, diabetic WKY might have already had dilated afferent arterioles. In contrast, diabetic SHR might have had relative afferent arteriolar vasoconstriction compared to diabetic WKY.

Angiotensin II mainly constricts efferent glomerular arterioles, thus contributing to the maintenance of glomerular capillary pressure and glomerular filtration $(10,21,27)$. Removal of the action of angiotensin II by ACEIs would lead to a fall in these parameters and reduced urinary protein excretion in both diabetic WKY and diabetic SHR. On the other hand, CCBs exert their vasodilatory action on afferent glomerular arterioles preferentially $(10,28)$, thus resulting in no change or in an increase in glomerular capillary pressure and no change in urinary protein excretion in spite of systemic blood pressure reduction in diabetic SHR. In diabetic WKY, in contrast, afferent arterioles might

Table 2. Parameters Following Treatment with Nifedipine, Benidipine, Captopril, Trandolapril or Vehicle (Control) for 12 Weeks in Diabetic Spontaneously Hypertensive Rats (SHR)

\begin{tabular}{lccccc}
\hline & Control & Nifedipine & Benidipine & Captopril & Trandolapril \\
& $n=7$ & $n=7$ & $n=7$ & $n=7$ & $n=7$ \\
\hline BUN (mg/dl) & $27.5 \pm 2.9$ & $25.9 \pm 0.7$ & $29.5 \pm 2.7$ & $30.0 \pm 2.0$ & $23.6 \pm 2.0$ \\
Scr $(\mathrm{mg} / \mathrm{dl})$ & $0.63 \pm 0.02$ & $0.61 \pm 0.02$ & $0.67 \pm 0.06$ & $0.55 \pm 0.07$ & $0.63 \pm 0.02$ \\
BG $(\mathrm{mg} / \mathrm{dl})$ & $546 \pm 13$ & $413 \pm 17^{*}$ & $473 \pm 38$ & $443 \pm 47$ & $477 \pm 31$ \\
TP $(\mathrm{g} / \mathrm{dl})$ & $5.2 \pm 0.2$ & $5.8 \pm 0.1^{*}$ & $5.5 \pm 0.2$ & $5.4 \pm 0.2$ & $5.8 \pm 0.2$ \\
Tcho (mg/dl) & $109 \pm 5$ & $117 \pm 6$ & $114 \pm 4$ & $104 \pm 3$ & $110 \pm 2$ \\
BW $(\mathrm{g})$ & $287 \pm 14$ & $289 \pm 7$ & $290 \pm 9$ & $279 \pm 9$ & $278 \pm 10$ \\
KW/100 g BW & $0.84 \pm 0.07$ & $0.64 \pm 0.02^{*}$ & $0.73 \pm 0.05$ & $0.79 \pm 0.07$ & $0.67 \pm 0.04$ \\
\hline
\end{tabular}

Results are expressed as mean \pm SEM. BUN, blood urea nitrogen; Scr, serum creatinine; BG, blood glucose; TP, serum total protein; Tcho, serum total cholesterol; $\mathrm{BW}$, body weight; $\mathrm{KW}$, kidney weight. ${ }^{*} p<0.05$ vs. control. 
already have been dilated before the administration of CCBs. Glomerular capillary pressure could then be directly influenced by systemic blood pressure, resulting in decreased glomerular pressure and urinary protein excretion in diabetic WKY.

In addition to the efferent vasoconstriction, angiotensin II has many other actions within the kidney, including effects on mesangial cell contraction and macromolecular uptake through the mesangium (29), glomerular permeability to proteins (30), tubular sodium reabsorption (31), and vasa recta blood flow (32). Morelli et al. (33) demonstrated that enalapril shifted glomerular pore size distribution to the smaller side in patients with established diabetic glomerulopathy. Inhibition of angiotensin II generation by ACEIs might induce more changes than glomerular hemodynamic parameters, and some of them might contribute to the renal protective effect of ACEIs.

Recent studies have suggested that compensatory renal hypertrophy may contribute to progressive glomerular injury independent of adaptive changes in glomerular hemodynamics $(21)$. In the present experiment, NIF, BEN and TRA significantly reduced kidney-to-body weight ratio in diabetic WKY. NIF also significantly reduced this parameter in diabetic SHR. However, antihypertrophic effects may not have been consistently related to the proteinuria in our experiments.

Blood glucose levels in BEN-treated WKY and in NIF-treated SHR were lower than in the respective controls. It still remains to be determined whether these results were due to specific actions of CCBs or due to heterogeneity of the induced diabetes (34, 35 ). In our preliminary study, we administered 60 $\mathrm{mg} / \mathrm{kg}$ of STZ to Sprague-Dawley rats, which are as susceptible as WKY to the diabetogenic actions of STZ, but about $40 \%$ of this strain died during the following 9 weeks of observation. Another way to make a diabetic model of rats which can survive during long study periods is to administer larger doses of STZ than we used in this experiment and to provide exogenous insulin to prevent extreme hyperglycemia. It is known that insulin has various actions other than controlling blood glucose. To avoid such actions of exogenously administered insulin, we administered smaller doses of STZ than previously reported.

In summary, proteinuria progressively increased in both STZ-induced diabetic WKY and SHR during the experimental period, and the latter model showed a more rapid rise. Treatment with ACEIs, CAP and TRA, reduced urinary protein excretion in both diabetic SHR and WKY. On the other hand, treatment with CCBs, NIF and BEN, reduced urinary protein excretion in diabetic WKY but not in diabetic SHR in spite of a comparable blood pressure reduction, partly because ACEIs may preferentially reduce the glomerular capillary pressure. In conclusion, our findings suggest that ACEIs could have more potent renal protective action than CCBs in this model of rats.

\section{Acknowledgments}

This study was partly supported by a grant from Miyagi Prefectural Kidney Association, Japan. We are grateful to Bayer Pharmaceut., Co., Tokyo, Japan, Kyowa Hakko Kogyo Co., Tokyo, Japan, Sankyo Co., Tokyo, Japan, and Nippon Roussel Co., Tokyo, Japan for supplying nifedipine, benidipine, captopril and trandolapril, respectively.

\section{References}

1. Drury PL: Diabetes and arterial hypertension. Diabetologica 1983; 24: 1-9.

2. Mogensen CE and Christensen CK: Predicting diabetic nephropathy in insulin-dependent patients. $N$ Engl J Med 1984; 311: 89-93.

3. Parving H, Anderson A, Smidt U, Svendsen P: Early aggressive anti-hypertensive treatment reduces rate of decline in kidney function in diabetic nephropathy. Lancet i; 1983: 1176-1179.

4. Parving $\mathrm{H}$, Andersen A, Smidt U, Hommel E, Mathiesen E, Svendsen P: Effect of antihypertensive treatment on kidney function in diabetic nephropathy. Br Med J 1987; 294: 1443-1447.

5. Marre M, Leblanc H, Suarez L, Guyenne TT, Menard J, Passa P: Converting enzyme inhibition and kidney function in normotensive diabetic patients with persistent microalbuminuria. $\mathrm{Br}$ Med J 1988; 297: 1092-1095.

6. Parving $\mathrm{H}$, Hommel E: Prognosis in diabetic nephropathy. Br Med J 1989; 299: 230-233.

7. Bedogna V, Valvo E, Casagrande $\mathrm{P}$, et al: Effects of ACE inhibition in normotensive patients with chronic glomerular disease and normal renal function. Kidney Int 1990; 38: 101-107.

8. Anderson S, Rennke HG, Garcia DL, Brenner BM: Short and long term of antihypertensive therapy in the diabetic rat. Kidney Int 1989; 36: 526-536.

9. Zats R, Dunn BR, Meyer TW, Anderson S, Rennke HG, Brenner BM: Prevention of diabetic glomerulopathy by pharmacological amelioration of glomerular capillary hypertension. J Clin Invest 1986; 77: 1925-1930.

10. Anderson S, Rennke HG, Brenner BM: Therapeutic advantage of converting enzyme inhibitors in arresting progressive renal disease associated with systemic hypertension in the rat. J Clin Invest 1986; 77: 1993-2000.

11. Cooper ME, Allen TJ, Macmillan P, Bach L, Jerums G, Doyle AE: Genetic hypertension accelerates nephropathy in the streptozotocin diabetic rat. $\mathrm{Am} \mathrm{J}$ Hypertens 1988; 1: 5-10.

12. Cooper ME, Allen TJ, O'Brien RC, et al: Effects of genetic hypertension on diabetic nephropathy in the rat - functional and structural characteristics. $J$ Hypertens 1988; 6: 1009-1016.

13. Steffes MW, Brown DM, Mauer SM: Diabetic glomerulopathy following unilateral nephropathy in the rat. Diabetes 1978; 27: 35-41.

14. O'Donnell MP, Kasiske BL, Daniels FX, Keane WF: Effects of nephron loss on glomerular hemodynamics and morphology in diabetic rats. Diabetes 1986; 35: 1011-1015.

15. Somani P, Singh HP, Saini RK, Rabinovitch A: Streptozotocin-induced diabetes in the spontaneously hypertensive rat. Metabolism 1979; 28: 1075-1077.

16. Fujii Y, Suzuki H, Katsumata H, Nakajima S, Saruta $\mathrm{T}$ : Hormonal and renal response to oral once-daily 
calcium entry blockers in normotensive and hypertensive persons. J Cardiovasc Phrmacol 1988; 11: 438-433.

17. Ikeda K, Nara Y, Yamori Y: Indirect systolic and mean blood pressure determination by a new tail cuff method in spontaneously hypertensive rats. Labo Animals 1991; 25: 26-29.

18. Taguma Y, Kitamoto Y, Futaki G, et al: Effect of captopril on heavy proteinuria in azotemic diabetics. $N$ Engl J Med 1985; 313: 1617-1620.

19. Heeg JE, De Jong PE, Van Der Hem GK, De Zeeuw: Reduction of proteinuria by converting enzyme inhibition. Kidney Int 1987; 32: 78-83.

20. Parving $\mathrm{HH}$, Hommel E, Smidt UM: Protection of kidney function and decrease in albuminuria by captopril in insulin dependent diabetes with nephropathy. $B r$ Med $J$ 1988; 297: 1086-1091.

21. Anderson S, Meyer TW, Rennke HG, Brenner BM: Control of glomerular hypertension limits glomerular injury in rats with reduced renal mass. $J$ Clin Invest 1985; 76: 612-619.

22. Beukers JJB, Van der Wal A, Hoedemaeker PJ, Weening JJ: Converting enzyme inhibition and progressive glomerulosclerosis in the rat. Kidney Int 1987; 32: 794-800.

23. Bjorck S, Mulec H, Johnsen SA, Nyberg G, Aurell $\mathrm{M}$ : Contrasting effects of enalapril and metoprolol on proteinuria in diabetic nephropathy. $B r$ Med J 1990; 300: $904-907$.

24. Hostetter TH, Troy JL, Brenner BM: Glomerular hemodynamics in experimental diabetes mellitus. Kidney Int 1981; 19: 410-415.

25. Zatz R, Meyer TW, Rennke HG, Brenner BM: Predominance of hemodynamic rather than metabolic factors in the pathogenesis of diabetic glomerulopathy. Proc Nat Acd Sci (USA) 1985; 82: 5963-5967.

26. Arendshorst WJ, Beierwaltes WH: Renal and nephron hemodynamics in spontaneously hyperten- sive rats. Am J Physiol 1970; 236: F246-F251.

27. Keane WF, Anderson S, Aurell M, De Zeeuw D, Narins R, Povar C: Angiotensin converting enzyme inhibitors and progressive renal insufficiency-Current experience and future directions. Ann Intern Med 1989; 111: 503-516

28. Meyer TW, Anderson S, Rennke HG, Brenner BM: Reversing glomerular hypertension stabilizes established glomerular injury. Kidney Int 1987; 31: $752-759$.

29. Raij L, Keane WF: Glomerular mesangium: Its function and relationship to angiotensin II. Am J Med 1985; 79 (suppl 3C): 24-30.

30. Remuzzi A, Puntorieri S, Battaglia C, Bertani T, Remuzzi G: Angiotensin converting enzyme inhibition ameliorates glomerular filtration of macromolecules and water and lessens glomerular injury in the rat. $J$ Clin Invest 1990; 85: 541-549.

31. Hall JE: Regulation of glomerular filtration and sodium excretion by angiotensin II. Fed Proc 1986; 45: $1431-1437$

32. Chou S-Y, Faubert PF, Porush JG: Contribution of angiotensin to the control of medullary haemodynamics. Fed Proc 1986; 45: 1438-1443.

33. Morelli E, Loon N, Meyer T, Peters W, Myers BD: Effect of converting-enzyme inhibition on barrier function in diabetic glomerulopathy. Diabetes 1990; 39: $76-82$.

34. Fada GZ, Akmal M, Soliman AR, Lipson LG, Massry SG: Correction of glucose intolerance and impaired insulin release of chronic renal failure by verapamil. Kidney Int 1989; 36: 773-779.

35. Sheu WHH, Swislocki ALM, Hoffmann B., Chen YDI, Reaven GM: Comparison of the effects of atenolol and nifedipine on glucose, insulin, and lipid metabolism in patients with hypertension. Am $J$ Hypertens 1991; 4: 199-205. 